\title{
Cloning and expression analysis of Wnt6 and Hox6 during intestinal regeneration in the sea cucumber Apostichopus japonicus
}

\author{
L.N. Sun ${ }^{1,2}$, H.S. Yang ${ }^{1}$, M.Y. Chen ${ }^{3}$ and D.X. Xu ${ }^{1,2}$ \\ ${ }^{1}$ Institute of Oceanology, Chinese Academy of Sciences, Qingdao, China \\ ${ }^{2}$ University of Chinese Academy of Sciences, Beijing, China \\ ${ }^{3}$ Ocean University of China, Qingdao, China \\ Corresponding authors: H.S. Yang / M.Y. Chen \\ E-mail: hshyang@ms.qdio.ac.cn / chenmuyan@gmail.com
}

Genet. Mol. Res. 12 (4): 5321-5334 (2013)

Received November 23, 2012

Accepted March 11, 2013

Published November 7, 2013

DOI http://dx.doi.org/10.4238/2013.November.7.7

\begin{abstract}
Many developmental genes play important roles in regeneration. Here, we cloned the two developmental genes, Wnt6 and Hox6, from Apostichopus japonicus by rapid amplification of cDNA ends (RACE) polymerase chain reaction (PCR). The Wnt6 full-length cDNA is $1140 \mathrm{bp}$ long with a 1029-bp open reading frame encoding 342 amino acids. The deduced Wnt6 protein contained a 22-amino acid signal peptide and a 274-amino acid mature peptide. The Hox6 (AjHBOX6) full-length cDNA contained $1312 \mathrm{bp}$ with a 966-bp open reading frame encoding 321 amino acids. Its deduced amino acid sequence included one homeodomain (60 amino acids) and three domains with low compositional complexity. Comparison and phylogenetic analysis revealed that Wnt6 and Hox6 in $A$. japonicus had the nearest relationship to those in sea urchins. Further expression analysis by real-time PCR showed that Wnt6 and Hox6 were apparently upregulated during intestine regeneration, which
\end{abstract}


suggested that they were involved in the intestinal regeneration of sea cucumbers.

Key words: Wnt6; Hox6; Sea cucumber; Intestinal regeneration

\section{INTRODUCTION}

It is widely accepted that the canonical $W n t$ pathway is involved in the activation of gene regulatory networks during development and regeneration (Hobmayer et al., 2000; Monga et al., 2001; Lengfeld et al., 2009; Gurley et al., 2010). Wnt genes encode a large family of secreted, cysteine-rich proteins that are critical mediators of key cell-cell signaling events in development and regeneration (Wodarz and Nusse, 1998; Logan and Nusse, 2004). To date, about 200 known Wnt genes have been subdivided into 16 subfamilies, Wnt1-Wnt16 (http://www.ncbi.nlm.nih.gov). Intriguingly, distinct $W n t$ genes have opposing roles in regeneration - some genes $(W n t 8)$ promote regeneration and some inhibit regeneration $(W n t 5 b)$ (Stoick-Cooper et al., 2007). Currently, the studies on Wnt6 demonstrated that it plays the role of promoting development and regeneration (Schubert et al., 2002; Geetha-Loganathan et al., 2006). Wnt6 encodes the 1 st pan-epidermal Wnt signaling molecule and promotes epithelial remodeling, myogenesis, and epithelial-mesenchymal transformation; besides, it activates endodermal genes in the endomesoderm gene regulatory network (Schubert et al., 2002; GeethaLoganathan et al., 2005, 2006; Croce et al., 2011).

Hox genes encode transcription factors that determine positional identity along the anteroposterior axis in a wide range of organisms to guide tissue differentiation (Bayascas et al., 1997; Leucht et al., 2008; Wang et al., 2009; Pfeifer et al., 2012). They encode Hox proteins that are accessory factors that bind to specific DNA sequences to activate or repress genes (Wang et al., 2009). The Hox genes determine progenitor cell fate and then pose the positional memory in wound healing and regeneration; for example, planarians can regenerate a head if it loses the head, and it can regenerate a tail if it loses the tail (Bayascas et al., 1997; Leucht et al., 2008). It is interesting to note that some Hox genes play different roles in development and regeneration; thus, these Hox genes are deemed truly "regeneration-specific" genes. For instance, Hoxc10L is not expressed during axolotl forelimb development, but it is expressed during forelimb regeneration (Carlson et al., 2001). The ancestral echinoderm's Hox genes contain at least 11 paralogous genes, which are not known for all echinoderm classes (Long and Byrne, 2001). Nine Hox-type sequences (three genes of the anterior: $\mathrm{HgHbox} 1, \mathrm{HgHbox} 2$, and HgHbox3; one of the medial: HgHbox5; and five of the posterior: HgHbox9, HgHbox 10, HgHbox 11, HgHbox 12, and $\mathrm{HgHbox} 13$ ) from the sea cucumber Holothuria glaberrima have been reported (Mendez et al., 2000). The Hox6 that was investigated in this experiment in sea cucumber is still unknown.

The sea cucumber Apostichopus japonicus is a common species along the East Asian coast, and this species has the capacity of perfectly regenerating viscera following evisceration. In recent years, an increasing number of scholars have focused on the field of visceral regeneration in sea cucumber (García-Arrarás et al., 1998; Xia and Xia, 2007). Thickened mesenteries are deemed the center of intestinal regeneration, and the dedifferentiating mesothelium provides the initial source of the intestine rudiment cells (García-Arrarás and Greenberg, 2001; García-Arrarás et al., 2011). Intestinal regeneration of sea cucumbers employs 
morphallaxis (mainly cell migration) at the early stage and epimorphosis (mainly cell division) at the later stage (García-Arrarás et al., 1998). Accompanying the development of new technology, researchers have screened candidate genes that were associated with visceral regeneration by gene microarray or RNA sequencing to study the molecular mechanism of visceral regeneration (Rojas-Cartagena et al., 2007; Ortiz-Pineda et al., 2009; Sun et al., 2011). The process of intestinal regeneration is complex and involves organogenesis, not merely wound healing. Therefore, many genes show differential expression during intestinal regeneration (Ortiz-Pineda et al., 2009). However, only a few genes playing important roles in intestinal regeneration in sea cucumbers have been thoroughly studied, such as Wnt9, Bmpl, ependymin, serum amyloid A, survivin, and mortalin (Santiago-Cardona et al., 2003; Suarez-Castillo et al., 2004; Zheng et al., 2006; Mashanov et al., 2010, 2012). Therefore, the molecular and genetic basis of intestinal regeneration still needs further study. Wnt6 and Hox6 were screened by our previous work involving expression profiling (Sun et al., 2011). Here, we investigated the mRNA transcripts of Wnt6 and Hox 6 and their expression during intestinal regeneration in sea cucumber A. japonicus. This is the 1st report to identify Wnt6 and Hox6 in sea cucumber. This study will provide insights into the roles of these developmental genes in injury-triggered regeneration of echinoderms.

\section{MATERIAL AND METHODS}

\section{Animals}

Adult sea cucumbers (A. japonicus; 70-100 g) were collected from the coast of Qingdao, Shandong Province, and cultured in the laboratory for 1 week in seawater at $15-17^{\circ} \mathrm{C}$ before the experiment. Evisceration was induced by injecting about $2 \mathrm{~mL} 0.35 \mathrm{M} \mathrm{KCl}$ to the coelom. The noneviscerated sea cucumbers (control) were fed once per day. All sea cucumbers were anesthetized in $6 \% \mathrm{MgCl}_{2}$ for about $1 \mathrm{~h}$ before being sacrificed. At least 5 individuals per stage $[3,7,10,14$, and 21 days postevisceration (dpe)] were used for studies. The dissected intestine was frozen and stored in liquid nitrogen.

\section{RNA extraction and cloning of full-length cDNA}

Total RNA of regenerative and normal intestines was extracted and DNase-treated using the RNeasy Mini Kit and RNase-Free DNase Set (Qiagen, Germany) following the manufacturer instructions. The quality and concentration of RNA were measured by NanoDrop 1000 (Thermo Fisher Scientific, USA).

To obtain the full-length cDNA of the Wnt6 and Hox6 genes, 5' and $3^{\prime}$ rapid amplification of the cDNA ends polymerase chain reaction (RACE PCR) was conducted (SMARTer ${ }^{\mathrm{TM}}$ RACE cDNA Amplification Kit, Clontech, CA, USA). 5'- and 3'-RACE-ready cDNA was synthesized following the manufacturer instructions. The 5'-RACE cDNA was synthesized in a 10- $\mu \mathrm{L}$ synthesis reaction as follows: 1) $2.75 \mu \mathrm{L}$ RNA and $1 \mu \mathrm{L}$ 5'-CDS Primer A were incubated in a tube at $72^{\circ} \mathrm{C}$ for $3 \mathrm{~min}$ and cooled at $42^{\circ} \mathrm{C}$ for $2 \mathrm{~min}$; 2) $1 \mu$ L SMARTer II A oligonucleotide was added; and 3) $2 \mu \mathrm{L} 5$ X First-Strand Buffer, $1 \mu \mathrm{L}$ dithiothreitol (DTT) $(20 \mathrm{mM}), 1 \mu \mathrm{L}$ dNTP mix $(10 \mathrm{mM})$, $0.25 \mu \mathrm{L}$ RNase inhibitor $(40 \mathrm{U} / \mu \mathrm{L})$, and $1 \mu \mathrm{L}$ reverse transcriptase (100 $\mathrm{U})$ were added to a final volume of $10 \mu \mathrm{L}$ and incubated at $42^{\circ} \mathrm{C}$ for $90 \mathrm{~min}$. The 3 '-RACE cDNA was synthesized using 
the 3'-CDS Primer A without the SMARTer II A oligonucleotide in the same reaction system.

We obtained a 512-bp expressed sequence tag for Wnt6 and a 515-bp expressed sequence tag for Hox6 from the transcriptome library of sea cucumber A. japonicus (Sun et al., 2011). According to the rules of primer design in the SMARTer ${ }^{\mathrm{TM}}$ RACE cDNA Amplification kit, gene-specific primers (GSP) for amplifying full-length cDNA were designed by the Primer Premier 5.0 software (Premier Biosoft International, Palo Alto, CA, USA). The $5^{\prime}$ end of $W n t 6$ was amplified with primers GSPwnt6F1, GSPwnt6F2, and universal primer mix (UPM) (Table 1), and the 5' end of the $A j H$ BOX6 sequence was amplified with primers GSPAjHbox6F1, GSPAjHbox6F2, (Table 1) and UPM using the 5'-RACE-ready cDNA as the template. The 3' end of Wnt6 and was amplified using GSPwnt6R1 and GSPwnt6R2 (Table 1), and the 3' end of Hox6 was amplified using GSPAjHbox6R1 and GSPAjHbox6R2 (Table 1). Both of these used the UPM primer and 3'-RACE-ready cDNA as a template. RACE PCR was conducted in a 50- $\mu \mathrm{L}$ amplification reaction mixture including the following: $2.5 \mu \mathrm{L}$ RACE-ready cDNA, $5 \mu \mathrm{L} 10 \mathrm{X}$ UPM, $1 \mu \mathrm{L}$ GSP, $5 \mu \mathrm{L} 10 \mathrm{X}$ advantage 2 PCR buffer, $1 \mu \mathrm{L}$ dNTP mix $(10 \mathrm{mM}), 1 \mu \mathrm{L} 50 \mathrm{X}$ advantage 2 polymerase mix, and $34.5 \mu \mathrm{L}$ PCR-grade water. The amplification cycle was $94^{\circ} \mathrm{C}$ for $1 \mathrm{~min} ; 35$ cycles of $94^{\circ} \mathrm{C}$ for $30 \mathrm{~s}, 68^{\circ} \mathrm{C}$ for $30 \mathrm{~s}$, and $72^{\circ} \mathrm{C}$ for $3 \mathrm{~min}$; and a final extension at $72^{\circ} \mathrm{C}$ for $3 \mathrm{~min}$ (Mastercycler Pro, Eppendorf, Germany).

\begin{tabular}{ll}
\multicolumn{2}{c}{ Table 1. Sequences of RACE PCR and real-time PCR primers. } \\
\hline Primer & Sequence \\
\hline Gspwnt6 F1 & 5'-TGGGGAGGATGCGGTGATAATATAGA-3' \\
Gspwnt6 R1 & 5'-AGATAGACCGTGGCATTTGCATTCAC-3' \\
Gspwnt6 F2 & 5'-GCACCGATGGTCGATGATCTTGTGTA-3' \\
Gspwnt6 R2 & 5'-ATACTCTGTGGCTCCTCTCCCGCAAC-3' \\
UPM & Long: 5'-CTAATACGACTCACTATAGGGCAAGCAGTGGTATCAACGCAGAGT-3' \\
& Short: 5'-CTAATACGACTCACTATAGGGC-3' \\
GSPAjHbox6F1 & 5'-GCCTCGGGACATTTGCTACCTATGA-3' \\
GSPAjHbox6R1 & 5'-TTGGTCTTGGTAAGATCCCGTTTGGA-3' \\
GSPAjHbox6F2 & 5'-CGGCAGACATACACGCGATATCAAAC-3' \\
GSPAjHbox6R2 & 5'-CGTCATCACCATGGTTACCTTCTCCA-3' \\
RTwnt6F & 5'-TAGTTCCAGTCAACGCGATATTT-3' \\
RTwnt6R & 5'-CGTTTCTCTGGTATCTGCTTGTT-3' \\
AjHbox6F & 5'-CGGTACGGTCAGACACTGAAT-3' \\
AjHbox6F & 5'-AGCTTGGTTAAAAGCACACGA-3' \\
NADHF & 5'-GTCCTACGACCCAATCTGGA-3' \\
NADHR & 5'-ATGAGCCTTGGTTACGTTGG-3' \\
\hline
\end{tabular}

The expected DNA fragments were eluted from the $1 \%$ agarose gel, ligated into the pMD19-T vector (Takara, Japan), and transformed into JM109 competent cells (Takara, Japan) following manufacturer instructions. Transformed cells were cultured overnight on Luria-Bertani (LB) agar plates containing $100 \mu \mathrm{g} / \mathrm{mL}$ ampicillin. White clones were selected and cultured in SOC medium containing $100 \mu \mathrm{g} / \mathrm{mL}$ ampicillin for $10 \mathrm{~h}$. The positive recombinant clones were sequenced by Beijing HUADA (Beijing, China). The sequences were analyzed and assembled by DNAStar software (DNAStar Inc., USA) to obtain the full-length cDNA.

\section{Sequence analysis}

The full-length cDNA sequence and deduced amino acid sequence of Wnt6 and Hox6 were analyzed using the basic local alignment search tool (BLAST) program at the National Center for Biotechnology Information (http://www.ncbi.nlm. nih.gov/blast) and the ExPASy 
server of the Swiss Institute of Bioinformatics (http://www.expasy.org/tools/). The functional sites or domains in the amino acid sequence were predicted with the simple modular architecture research tool SMART version 4.0 (http://www.smart.embl-heidelberg.de/). The molecular mass and theoretical isoelectric point were predicted using the compute $\mathrm{pI} / \mathrm{Mw}$ tool (http://www.expasy.org/tools/pi_tool.html). Multiple sequence alignment and phylogenetic analysis were conducted using the program Clustal W (http://www.ebi.ac.uk/clustalW) and the Mega4.0 software.

\section{Real-time PCR analysis of Wnt6 and Hox6 mRNA expression}

We analyzed the mRNA expression of Wnt6 and Hox6 during intestinal regeneration in sea cucumber $A$. japonicus using real-time PCR. Total RNA extraction was carried out by the methods described above. The 1 st strand cDNA was synthesized in a $25-\mu \mathrm{L}$ reaction system as follows. First, $4 \mu \mathrm{L}$ RNA and $1 \mu \mathrm{L}$ oligodT 18 were denatured at $70^{\circ} \mathrm{C}$ for $5 \mathrm{~min}$. Then, $1 \mu \mathrm{L}$ M-MLV reverse transcriptase (Promega), $5 \mu \mathrm{L}$ M-MLV buffer $(25 \mathrm{mM} \mathrm{KCl}, 10 \mathrm{mM}$ Tris$\mathrm{HCl}, 0.6 \mathrm{mM} \mathrm{MgCl}$, and $2 \mathrm{nM}$ DTT, $\mathrm{pH} 8.3$ ), $5 \mu \mathrm{L} \mathrm{dNTP}, 1 \mu \mathrm{L}$ ribonuclease inhibitor, and $8 \mu \mathrm{L}$ RNase-free water were added at $42^{\circ} \mathrm{C}$ for $1 \mathrm{~h}$. The synthesized cDNA was diluted with RNase-free water and stored at $-80^{\circ} \mathrm{C}$ for subsequent quantitative real-time PCR.

The mRNA expression levels of Wnt6 and Hox6 were determined using the SYBR Green ${ }^{\circledR}$ real-time PCR assay with an Eppendorf Mastercycler ${ }^{\circledR}$ ep realplex (Eppendorf, Hamburg, Germany). The amplification volume was $25 \mu \mathrm{L}$, and it contained $12.5 \mu \mathrm{L}$ SYBR Green Master Mix (Takara), $0.5 \mu \mathrm{L}$ (each) forward and reverse primer $(10 \mu \mathrm{M})$ (RTwnt6F, RTwnt6R; AjHbox6F, AjHbox6R) (Table1), $1 \mu \mathrm{L}$ diluted cDNA, and $10.5 \mu \mathrm{L}$ RNase-free water. Thermal cycling was as follows: 1) $95^{\circ} \mathrm{C}$ for $5 \mathrm{~s}$ and 2) 40 cycles at $95^{\circ} \mathrm{C}$ for $10 \mathrm{~s}, 60^{\circ} \mathrm{C}$ for $20 \mathrm{~s}$, and $72^{\circ} \mathrm{C}$ for $30 \mathrm{~s}$. The melting curve analysis of the amplification products was performed to demonstrate the specificity of the PCR products. NADH dehydrogenase (NADHF, NADHR, Table 1) was used as a housekeeping gene for internal standardization. The $2^{-\Delta \Delta \mathrm{CT}}$ method was used to analyze the expression level of $W n t 6$ and Hox 6 mRNA. All data are reported as means $\pm \mathrm{SE}(\mathrm{N}=5)$, and the level of statistical significance was set at $\mathrm{P}<0.05$. Analysis was carried out using the SPSS16 software.

\section{RESULTS}

\section{Characterization, homology, and phylogenetic analyses of $A$. japonicus Wnt6 full-length cDNA}

The Wnt6 full-length cDNA contained 1140 nucleotides, which included a 2-bp 5'-untranslated region (UTR), a 109-bp 3'-UTR, and a 1029-bp open reading frame (ORF) (positions 3-1031) encoding 342 amino acids with a predicted molecular mass of $38 \mathrm{kDa}$ and a theoretical isoelectric point of 8.82 (Figure 1). The cDNA sequence of the Wnt6 gene was deposited in NCBI under accession No. JQ753331. The 1st 22 amino acids (positions 1-22) composed a signal peptide, and 274 amino acids (positions 38-311) composed the Wnt6 mature peptide.

Sequences of Wnt6 from invertebrate and vertebrate species were downloaded and used for homology and phylogenetic analyses. BLAST analysis revealed that Wnt6 from A. japonicus shared significant homology with that from Paracentrotus lividus (AEO92036.1, 51.7\% identity), Strongylocentrotus purpuratus (XP_790077.1, 51.4\% identity), Branchiostoma floridae 
(XP_002598625.1, 46.9\% identity), and Xenopus laevis (ABY53107.1, 45.7\% identity) (Figure 2).

A phylogenetic tree was constructed by analyzing the amino acid sequence of A. japonicus Wnt6 and sequences from other invertebrate and vertebrate species. The tree indicated that the evolution of Wnt6 was almost in accordance with the evolution of species. $A$. japonicus Wnt6 shared greater identity with the sea urchins than with other species (Figure 3).

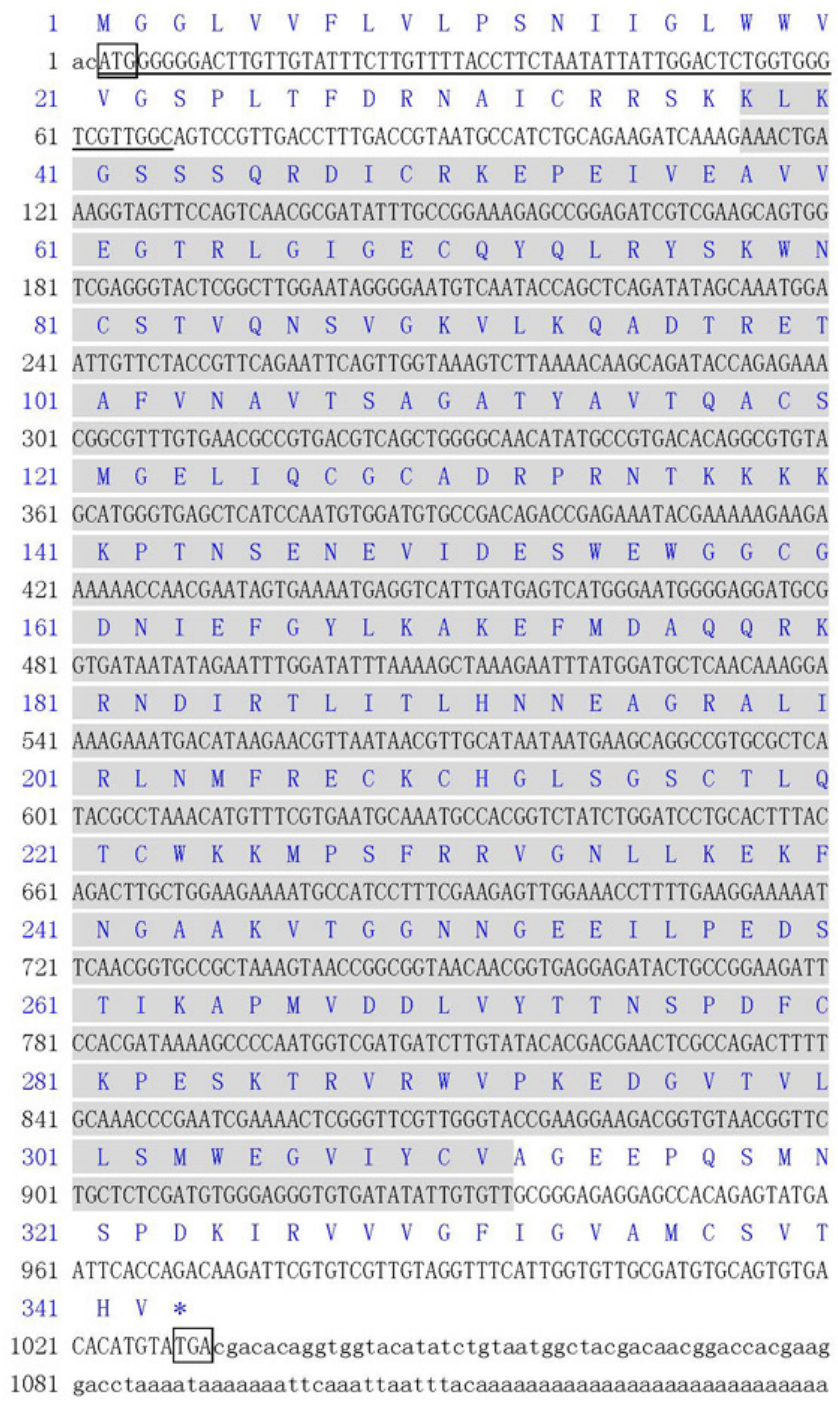

Figure 1. Nucleotide sequence (1140 bp) of the Apostichopus japonicus Wnt6 gene (accession No. JQ753331) aligned with its predicted amino acid (AA) sequence (capital single-letter code). The nucleotides and AA residues are numbered on the left. The whole nucleotide sequence includes 2-bp 5'-untranslated region (UTR), a 109-bp 3'-UTR, and a 1029-bp open-reading frame (342 AA). The start and stop codons are included in a box. The stop codon is indicated by an asterisk. The sequences encoding signal peptide are underlined and the sequences encoding mature peptide are highlighted as gray region. 


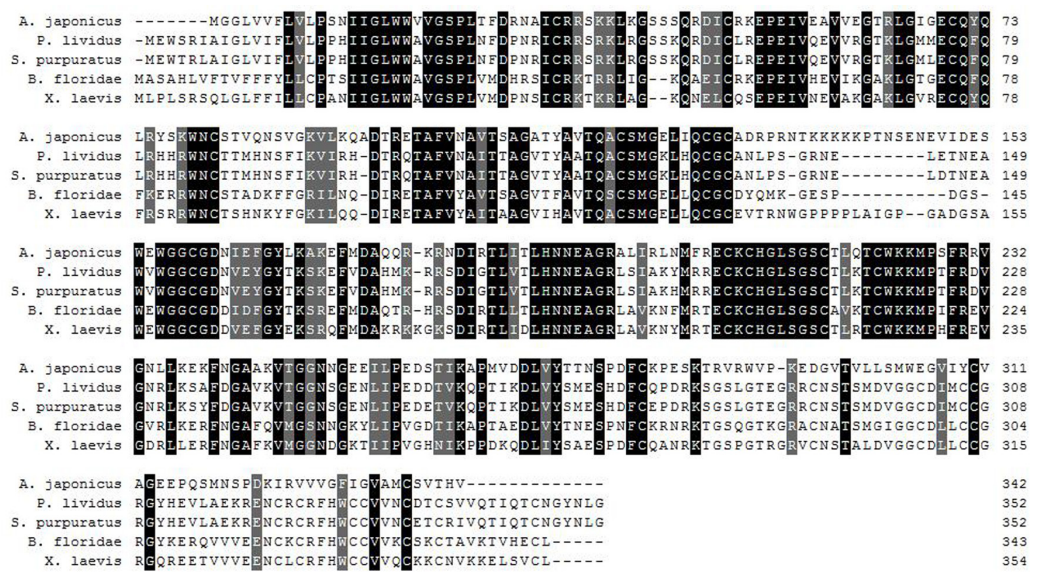

Figure 2. Amino acid alignment of Apostichopus japonicus and other animal Wnt6 sequences. The protein sequences deduced were used in the analysis using the Clustal W sequence alignment program. The black shadow region indicates positions where all sequences share the same amino acid residue. The species and the GenBank accession No. are as follows: A. japonicus (JQ753331), P. lividus (Paracentrotus lividus, AEO92036.1), S. purpuratus (Strongylocentrotus purpuratus, XP_790077.1), B. floridae (Branchiostoma floridae, XP_002598625.1), and X. laevis (Xenopus laevis, ABY53107.1).

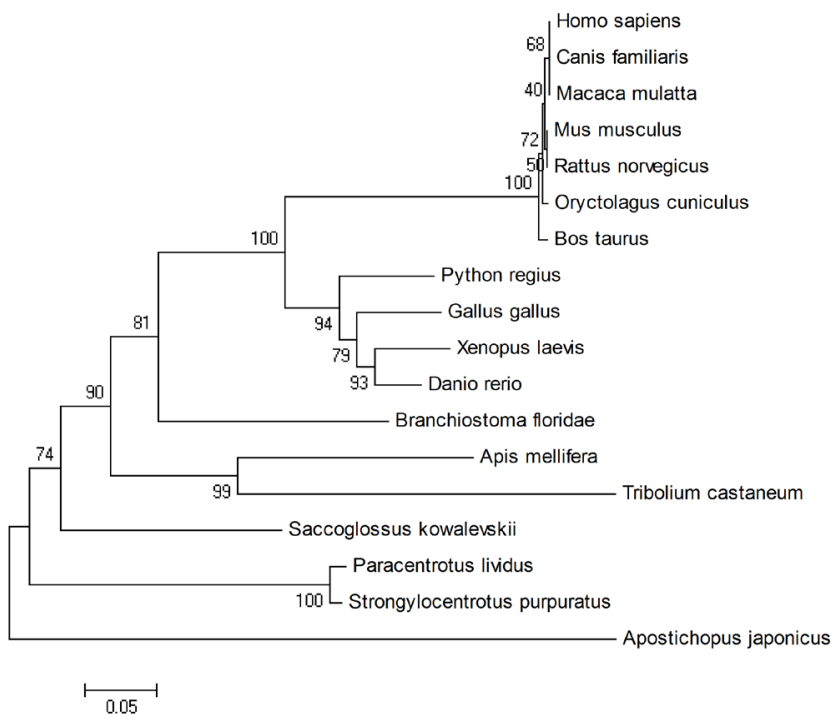

Figure 3. Phylogenetic tree constructed by neighbor-joining method based on the amino acid sequences of Wnt6 from different animals. Unrooted tree generated using a sequence distance method (neighbor-joining) from Clustal $\mathrm{X}$ alignments. The tree topology was evaluated by 1000 replications bootstraps and numbers on each branch of the tree represent bootstrap support value. The sequences were acquired from the GenBank as follows: Paracentrotus lividus (AEO92036.1), Strongylocentrotus purpuratus (XP_790077.1), Branchiostoma floridae (XP_002598625.1), Xenopus laevis (ABY53107.1), Gallus gallus (NP_001007595.1), Danio rerio (XP_003199237.1), Mus musculus (AAA40569.1), Rattus norvegicus (NP_001101696.1), Bos Taurus (NP_001192492.1), Homo sapiens (NP_006513.1), Macaca mulatta (XP_001095541.1), Apis mellifera (XP 396945.4), Oryctolagus cuniculus (XP 002712638.1), Canis familiaris (XP_5456̄77.2), Saccoglossus kowalevskii (Nי NP_001161676.1), Python regius (ACȲ68091.1), Tribolium castaneum (EFA04620.1). 


\section{Characterization, homology, and phylogenetic analyses of $A$. japonicus $A$ JHBOX6 (Hox6) full-length cDNA}

The AjHBOX6 full-length cDNA contained 1312 nucleotides, which included a 91-bp 5'-UTR, a 254-bp 3'-UTR, and a 966-bp ORF (positions 92-1057) encoding 321 amino acids with a predicted molecular mass of $36.16 \mathrm{kDa}$ and a theoretical isoelectric point of 5.86 (Figure 4). The cDNA sequence of the AjHBOX6 gene was deposited in NCBI under accession number JQ753332. Sixty amino acids (positions 217-276) composed the conserved domain of Hox genes - the homeodomain, which is a DNA-binding site. Additionally, the amino acid sequence included three low compositional complexity domains (positions 125-139, 181-195, and 303-321). This could be because AjHBOX6 is a transcription factor, and low compositional complexity regions are usually involved in flexible binding sites associated with specific functions (Coletta et al., 2010).

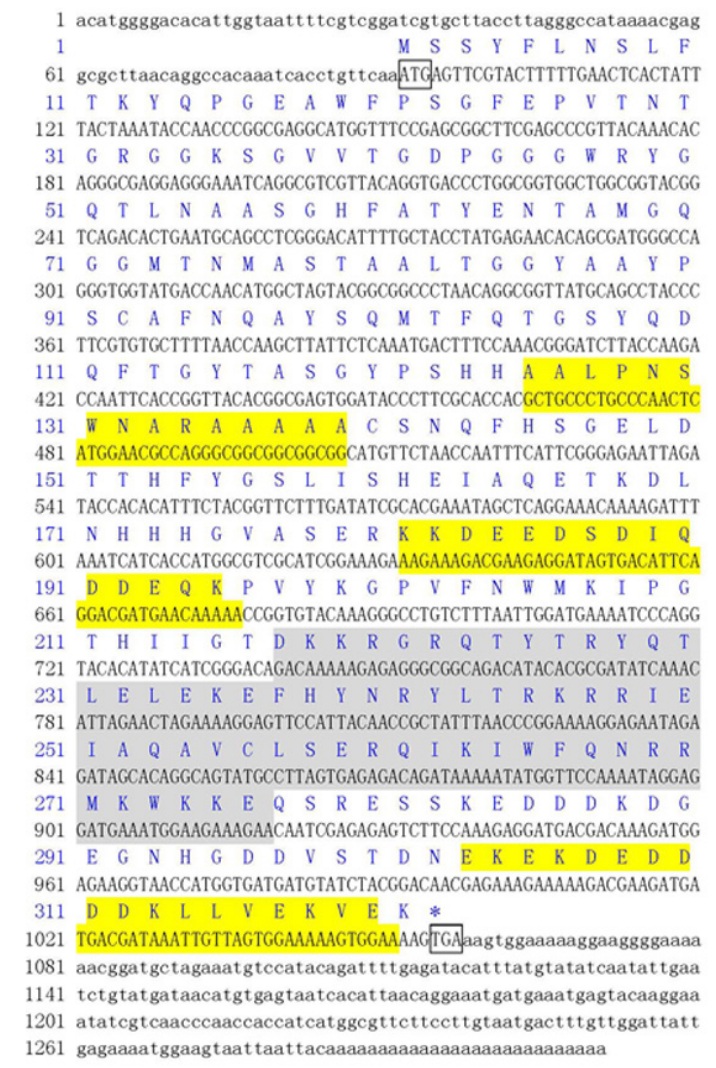

Figure 4. Nucleotide sequence (1312 bp) of the Apostichopus japonicus AjHbox6 gene (accession No. JQ753332) aligned with its predicted amino acid (AA) sequence (capital single-letter code). The nucleotides and AA residues are numbered on the left. The whole nucleotide sequence includes a 91-bp 5'-untranslated region (UTR), a 254-bp 3'-UTR, and a 966-bp open-reading frame (321 AA). The start and stop codons are included in a box. The stop codon is indicated by an asterisk. The conserved consensus sequences of Hox genes are shadowed with light gray. Low compositional complexity domains are shadowed with yellow. 
Sequences of AjHBOX6 from invertebrate and vertebrate species were downloaded and used for homology and phylogenetic analyses. BLAST analysis revealed that AjHBOX6 from A. japonicus shared significant homology with HEHBOX6 from Strongylocentrotus purpuratus (XP_793141.1, 38.9\% identity), HOX8 from Metacrinus rotundus (BAF43726.1, $37.1 \%$ identity), HOX8 from Balanoglossus simodensis (BAH96551.1, 31.8\% identity), and HOX7 from Branchiostoma lanceolatum (ACJ74388.1, 33\% identity) (Figure 5).

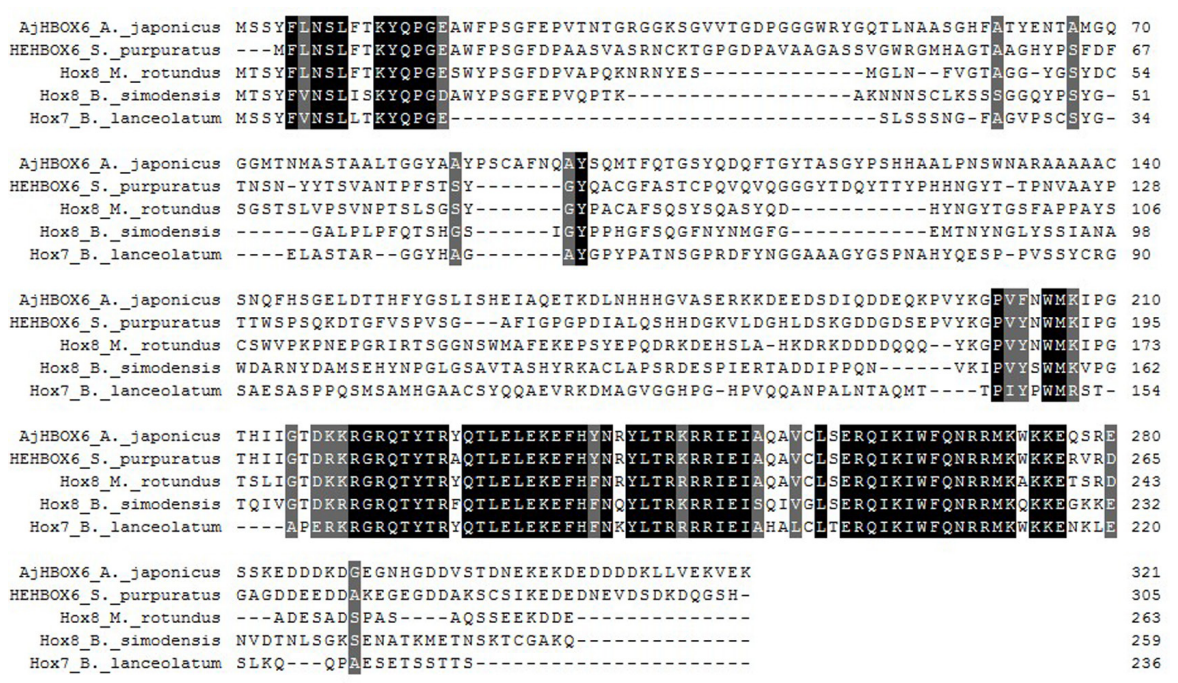

Figure 5. Amino acid alignment of Apostichopus japonicus AjHbox6 and other animal Hox sequences. The deduced protein sequences were used in the analysis using Clustal W sequences alignment program. The black shadow region indicates positions where all sequences share the same amino acid residue. The species and the GenBank accession No. are as follows: A. japonicus (JQ753332), S. purpuratus (Strongylocentrotus purpuratus, XP_793141.1), M. rotundus (Metacrinus rotundus, BAF43726.1), B. simodensis (Balanoglossus simodensis, BAH96551.1), and B. lanceolatum (Branchiostoma lanceolatum, ACJ74388.1).

A phylogenetic tree was constructed by analyzing the amino acid sequences of $A$. japonicus AjHBOX6 and sequences from other invertebrate and vertebrate species. The tree indicated that the evolution of Hox6, Hox7, and Hox8 was very conservative. A. japonicus AjHBOX6 shared greater identity with HEHBOX6 from the sea urchins than other species (Figure 6).

\section{Expression profile of $\mathrm{Wnt6}$ and $\mathrm{AjHBOX6}(\mathrm{Hox} 6)$ mRNA during intestine regeneration}

The mRNA expression level of Wnt6 and AjHBOX6 during intestinal regeneration was investigated using quantitative real-time PCR with NADH dehydrogenase as an internal control gene (Figures 7 and 8). One peak in the melting curve was detected, which indicated that the PCR product was specifically amplified (data not shown). Additionally, the amplified product was determined by electrophoresis and sequencing.

First, Wnt 6 was expressed in the normal intestine. Moreover, the Wnt 6 mRNA expression level at first increased and then decreased during intestinal regeneration in A. japonicus. At 3 and 7 dpe, the expression level of Wnt6 was upregulated 4.06 and 10.42 fold of the con- 
trol, respectively. After that, the expression level of Wnt6 gradually decreased to 7.56 and 3.61 fold of the expression in the control at 14 and 21 dpe, respectively.

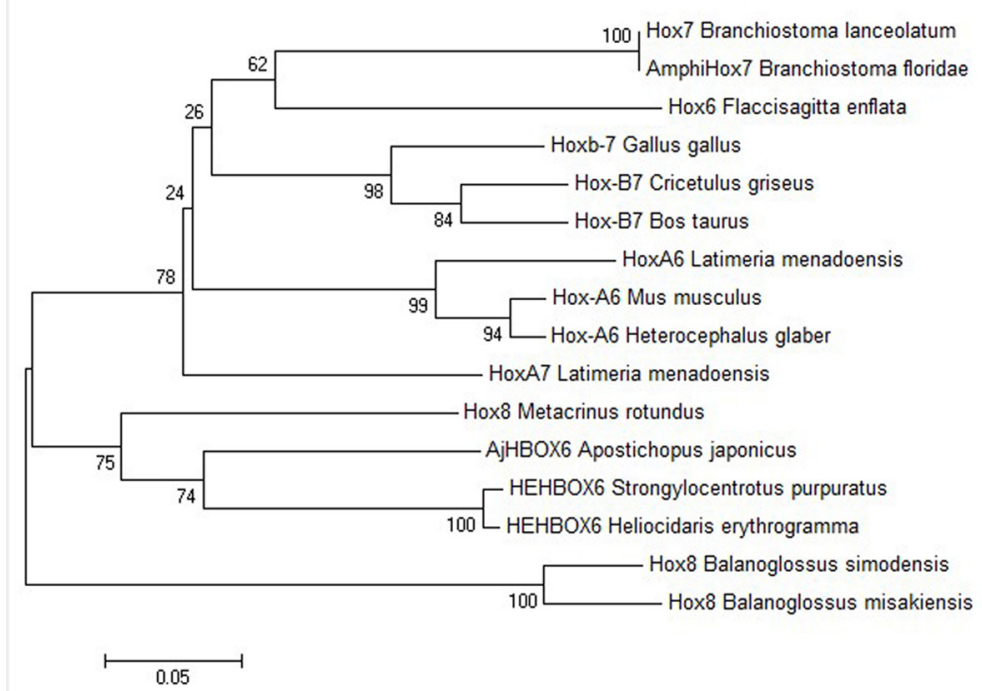

Figure 6. Phylogenetic tree constructed by neighbor-joining method based on the amino acid sequences of Hox genes from different animals. Unrooted tree generated using a sequence distance method (neighbor-joining) from Clustal X alignments. The tree topology was evaluated by 1000 replication bootstraps and numbers on each branch of the tree represent bootstrap support value. The sequences were acquired from the GenBank as follows: Hox8 (Metacrinus rotundus) (BAF43726.1), Hox8 (Balanoglossus simodensis) (BAH96551.1), HEHBOX6 (Heliocidaris erythrogramma) (AAB09405.1), Hox8 (Balanoglossus misakiensis) (BAH23877.1), Hox7 (Branchiostoma lanceolatum) (ACJ74388.1), AmphiHox7 (Branchiostoma floridae) (ABX39491.1), Hoxb-7 (Gallus gallus) (BAD95554.1), Hox-B7 (Cricetulus griseus) (EGW05241.1), Hox-B7 (Bos taurus) (DAA18571.1), HoxA7 (Latimeria menadoensis) (AAO43020.1), HoxA6 (Latimeria menadoensis) (ACL81438.1), Hox6 (Flaccisagitta enflata)(ABS18813.1), Hox-A6 (Mus musculus) (NP_034584.1), Hox-A6 (Heterocephalus glaber) (EHB07215.1).

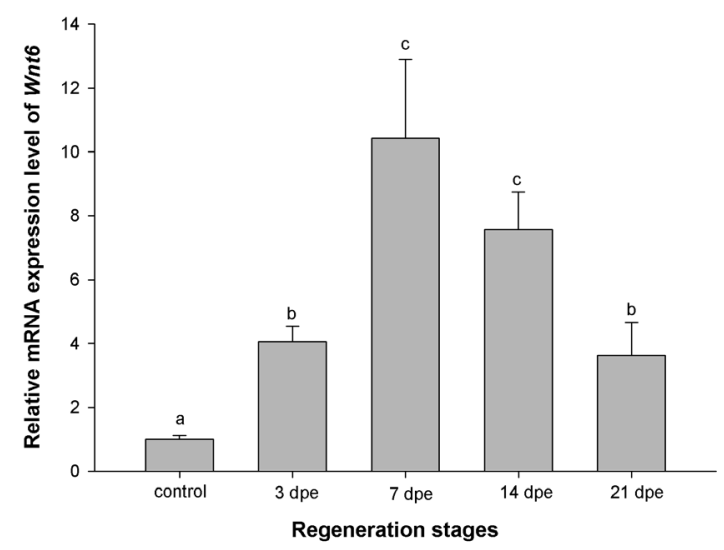

Figure 7. Relative expression levels of Apostichopus japonicus Wnt6 during intestine regeneration. Control= normal intestine; 3, 7, 14, 21dpe = regenerative intestine at 3, 7, 10, 14, and 21 days postevisceration. The values were normalized against NADH. Different lowercase letters indicate significant differences $(\mathrm{P}<0.05)$. Data are reported as means $\pm \mathrm{SE}(\mathrm{N}=5)$. 


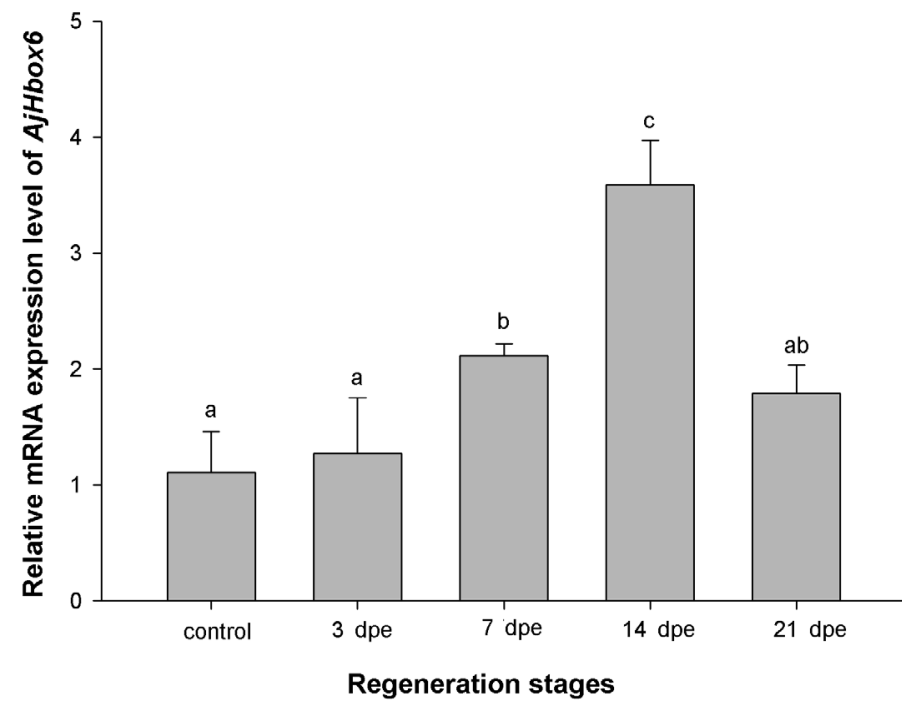

Figure 8. Relative expression levels of Apostichopus japonicus AjHbox6 during intestine regeneration. Control $=$ normal intestine; $3,7,14,21 \mathrm{dpe}=$ the regenerative intestine at $3,7,10,14$, and 21 days postevisceration. The values were normalized against NADH. Different lowercase letters indicate significant differences $(\mathrm{P}<0.05)$. Data are reported as means $\pm \mathrm{SE}(\mathrm{N}=5)$.

During intestinal regeneration in A. japonicus, the AjHBOX6 mRNA expression increased initially and then decreased. The AjHBOX6 mRNA expression level was not significantly increased at 3 dpe. Until 7 and 14 dpe, the expression level of Wnt6 was upregulated 2.11 and 3.59 fold of the level in the control. Then, the expression level of Wnt6 gradually decreased to the control level at 21 dpe.

\section{DISCUSSION}

Wnt6 was expressed in the normal intestine, which implied that it is necessary to maintain the normal life activity of $A$. japonicus. Moreover, the Wnt6 mRNA expression level at first increased and then decreased during intestinal regeneration in A. japonicus. Our previous histological studies demonstrated that the process of intestinal regeneration in $A$. japonicus was divided into five significant stages: wound healing (0-3 dpe), blastema formation (3-7 dpe), lumen formation (7-14 dpe), intestinal differentiation (14-21 dpe), and intestinal growth (14-21 dpe) (Xia and Xia, 2007). Taken together, Wnt6 began to have an impact on intestinal regeneration at the stage of blastema formation, and its transcript expression was maintained at a high level at the stage of lumen formation and intestine differentiation. After that, when the intestine has finished differentiation, the expression level of Wnt6 gradually decreased to nearly the level of the control intestine. For the studies on regeneration in several animals including rat, it was found that Wnt signaling was required for the formation and proliferation of progenitor cells of the blastema (Monga et al., 2001; Stoick-Cooper et al., 2007; Lengfeld et al., 2009). Experiments on the egg development of sea urchin have verified that Wnt6 is necessary for the activation of endodermal genes in the endomesoderm gene regulatory net- 
work (Croce et al., 2011). Therefore, Wnt6 is likely to play an important role in the activation of many genes to initiate intestine regeneration. García-Arrarás et al. demonstrated that the epithelial-mesenchymal transition provided the initial source of cells for the formation of the intestine blastema in sea cucumber H. glaberrima (García-Arrarás et al., 2011). Furthermore, Schubert et al. observed that the precise sites of Wnt6 expression coincided with the epithelial-mesenchymal transformation in the chick embryo (Schubert et al., 2002). Above all, Wnt6 responded to intestinal regeneration in A. japonicus, and it plays an important role in intestinal regeneration in A. japonicus.

Hox genes that determine the regional identities of newly formed segments play an impotent role in regeneration in a wide range of animals (Simon and Tabin, 1993; Bayascas et al., 1997; Khan et al., 1999; Pfeifer et al., 2012). They have attracted many scholars' attention in regeneration research. Just like Wnt6, the AjHBOX6 mRNA was also expressed in the normal intestine of $A$. japonicus, suggesting that its gene product was required to maintain normal life. However, not all Hox genes are detected in normal tissue; for example, Hox-4.5 transcripts were not detected in normal limbs of newts (Simon and Tabin, 1993). Therefore, not all Hox genes are needed to maintain normal life. Hox6 belongs to the medial cluster of the Hox gene family. Hox6 was found to be overexpressed in the thoracic region of mouse embryos (Gaunt et al., 1988). It was also found to play a role in motor neuron diversity and connectivity (Dalla Torre di Sanguinetto et al., 2008). During intestinal regeneration in $A$. japonicus, the AjHBOX6 mRNA expression level was not significantly increased at 3 dpe. Until 7 and 14 dpe, the expression level of Wnt6 was upregulated. Then, the expression level of Wnt6 gradually decreased to the control level at 21 dpe. AjHBOX6 was re-expressed in later intestinal regeneration stages: lumen formation and intestine differentiation. This phenomenon was not special; it has been observed in other species. For example, three Hox genes (Xhoxc10, XHoxa13, and XHoxd13) showed different expression patterns in limb regeneration of Xenopus: Xhoxc10 was upregulated when cells dedifferentiated in the blastema, whereas $X H o x a 13$ was re-expressed slightly in later regeneration, and XHoxd 13 was not expressed until late regeneration (Christen et al., 2003). Hox cluster genes have been demonstrated to play distinct roles in regeneration: 1) they play roles in wound healing and setting up regeneration that are different from their roles in development, and 2) they specify positional identity in regeneration similar to their roles in development (Gardiner et al., 1995; Carlson et al., 2001). Therefore, according to its overexpression at the stages of lumen formation and intestine differentiation, AjHBOX6 may belong to the 2nd group that guides intestine differentiation to anterior, middle, and posterior intestine.

\section{ACKNOWLEDGMENTS}

Research supported by the National Natural Science Foundation of China (\#41076103).

\section{REFERENCES}

Bayascas JR, Castillo E, Munoz-Marmol AM and Salo E (1997). Planarian Hox genes: novel patterns of expression during regeneration. Development 124: 141-148.

Carlson MR, Komine Y, Bryant SV and Gardiner DM (2001). Expression of Hoxb13 and Hoxc10 in developing and regenerating axolotl limbs and tails. Dev. Biol. 229: 396-406.

Christen B, Beck CW, Lombardo A and Slack JM (2003). Regeneration-specific expression pattern of three posterior Hox

Genetics and Molecular Research 12 (4): $5321-5334$ (2013)

CFUNPEC-RP www.funpecrp.com.br 
genes. Dev. Dyn. 226: 349-355.

Coletta A, Pinney JW, Solis DY, Marsh J, et al. (2010). Low-complexity regions within protein sequences have positiondependent roles. BMC Syst. Biol. 4: 43.

Croce J, Range R, Wu SY, Miranda E, et al. (2011). Wnt6 activates endoderm in the sea urchin gene regulatory network. Development 138: 3297-3306.

Dalla Torre di Sanguinetto SA, Dasen JS and Arber S (2008). Transcriptional mechanisms controlling motor neuron diversity and connectivity. Curr. Opin. Neurobiol. 18: 36-43.

García-Arrarás JE and Greenberg MJ (2001). Visceral regeneration in holothurians. Microsc. Res. Tech. 55: 438-451.

García-Arrarás JE, Estrada-Rodgers L, Santiago R, Torres II, et al. (1998). Cellular mechanisms of intestine regeneration in the sea cucumber, Holothuria glaberrima Selenka (Holothuroidea:Echinodermata). J. Exp. Zool. 281: 288-304.

García-Arrarás JE, Valentin-Tirado G, Flores JE, Rosa RJ, et al. (2011). Cell dedifferentiation and epithelial to mesenchymal transitions during intestinal regeneration in H. glaberrima. BMC Dev. Biol. 11: 61.

Gardiner DM, Blumberg B, Komine Y and Bryant SV (1995). Regulation of HoxA expression in developing and regenerating axolotl limbs. Development 121: 1731-1741.

Gaunt SJ, Sharpe PT and Duboule D (1988). Spatially restricted domains of homeo-gene transcripts in mouse embryos: relation to a segmented body plan. Development 104: 169-179.

Geetha-Loganathan P, Nimmagadda S, Prols F, Patel K, et al. (2005). Ectodermal Wnt-6 promotes Myf5-dependent avian limb myogenesis. Dev. Biol. 288: 221-233.

Geetha-Loganathan P, Nimmagadda S, Huang R, Scaal M, et al. (2006). Role of Wnt-6 in limb myogenesis. Anat. Embryol. 211: 183-188.

Gurley KA, Elliott SA, Simakov O, Schmidt HA, et al. (2010). Expression of secreted Wnt pathway components reveals unexpected complexity of the planarian amputation response. Dev. Biol. 347: 24-39.

Hobmayer B, Rentzsch F, Kuhn K, Happel CM, et al. (2000). WNT signalling molecules act in axis formation in the diploblastic metazoan Hydra. Nature 407: 186-189.

Khan PA, Tsilfidis C and Liversage RA (1999). Hox C6 expression during development and regeneration of forelimbs in larval Notophthalmus viridescens. Dev. Genes Evol. 209: 323-329.

Lengfeld T, Watanabe H, Simakov O, Lindgens D, et al. (2009). Multiple Wnts are involved in Hydra organizer formation and regeneration. Dev. Biol. 330: 186-199.

Leucht P, Kim JB, Amasha R, James AW, et al. (2008). Embryonic origin and Hox status determine progenitor cell fate during adult bone regeneration. Development 135: 2845-2854.

Logan CY and Nusse R (2004). The Wnt signaling pathway in development and disease. Annu. Rev. Cell Dev. Biol. 20: 781-810.

Long S and Byrne M (2001). Evolution of the echinoderm Hox gene cluster. Evol. Dev. 3: 302-311.

Mashanov VS, Zueva OR, Rojas-Catagena C and Garcia-Arraras JE (2010). Visceral regeneration in a sea cucumber involves extensive expression of survivin and mortalin homologs in the mesothelium. BMC Dev. Biol. 10: 117.

Mashanov VS, Zueva OR and Garcia-Arraras JE (2012). Expression of Wnt9, TCTP, and Bmp1/T1l in sea cucumber visceral regeneration. Gene Expr. Patterns. 12: 24-35.

Mendez AT, Roig-Lopez JL, Santiago P, Santiago C, et al. (2000). Identification of Hox gene sequences in the sea cucumber Holothuria glaberrima Selenka (Holothuroidea: Echinodermata). Mar. Biotechnol. 2: 231-240.

Monga SP, Pediaditakis P, Mule K, Stolz DB, et al. (2001). Changes in WNT/beta-catenin pathway during regulated growth in rat liver regeneration. Hepatology 33: 1098-1109.

Ortiz-Pineda PA, Ramirez-Gomez F, Perez-Ortiz J, Gonzalez-Diaz S, et al. (2009). Gene expression profiling of intestinal regeneration in the sea cucumber. BMC Genomics 10: 262.

Pfeifer K, Dorresteijn AW and Frobius AC (2012). Activation of Hox genes during caudal regeneration of the polychaete annelid Platynereis dumerilii. Dev. Genes Evol. 222: 165-179.

Rojas-Cartagena C, Ortiz-Pineda P, Ramirez-Gomez F, Suarez-Castillo EC, et al. (2007). Distinct profiles of expressed sequence tags during intestinal regeneration in the sea cucumber Holothuria glaberrima. Physiol. Genomics 31: 203-215.

Santiago-Cardona PG, Berrios CA, Ramirez F and Garcia-Arraras JE (2003). Lipopolysaccharides induce intestinal serum amyloid A expression in the sea cucumber Holothuria glaberrima. Dev. Comp Immunol. 27: 105-110.

Schubert FR, Mootoosamy RC, Walters EH, Graham A, et al. (2002). Wnt6 marks sites of epithelial transformations in the chick embryo. Mech. Dev. 114: 143-148.

Simon HG and Tabin CJ (1993). Analysis of Hox-4.5 and Hox-3.6 expression during newt limb regeneration: differential regulation of paralogous Hox genes suggest different roles for members of different Hox clusters. Development 117: 1397-1407.

Stoick-Cooper CL, Weidinger G, Riehle KJ, Hubbert C, et al. (2007). Distinct Wnt signaling pathways have opposing roles in appendage regeneration. Development 134: 479-489.

Genetics and Molecular Research 12 (4): 5321-5334 (2013)

CFUNPEC-RP www.funpecrp.com.br 
Suarez-Castillo EC, Medina-Ortiz WE, Roig-Lopez JL and Garcia-Arraras JE (2004). Ependymin, a gene involved in regeneration and neuroplasticity in vertebrates, is overexpressed during regeneration in the echinoderm Holothuria glaberrima. Gene 334: 133-143.

Sun L, Chen M, Yang H, Wang T, et al. (2011). Large scale gene expression profiling during intestine and body wall regeneration in the sea cucumber Apostichopus japonicus. Comp Biochem. Physiol. Part D. Genomics Proteomics 6: $195-205$.

Wang KC, Helms JA and Chang HY (2009). Regeneration, repair and remembering identity: the three Rs of Hox gene expression. Trends Cell Biol. 19: 268-275.

Wodarz A and Nusse R (1998). Mechanisms of Wnt signaling in development. Annu. Rev. Cell Dev. Biol. 14: 59-88.

Xia W and Xia L (2007). The morphological and histological observation of regeneration of alimentary tract in sea cucumber Apostichopus japonicus. J. Dalian Fish. Univ. 22: 340-346.

Zheng FX, Sun XQ, Fang BH, Hong XG, et al. (2006). Comparative analysis of genes expressed in regenerating intestine and non-eviscerated intestine of Apostichopus japonicus Selenka (Aspidochirotida: Stichopodidae) and cloning of ependymin gene. Hydrobiologia 571: 109-122. 